\title{
Percepciones y actitudes sobre algunos temas de la reforma política
}

\author{
Julia Isabel Flores* \\ Omar Alejandre* \\ Miguel Ángel García Olivo* \\ Salvador Vázquez del Mercado*
}

\section{Sumario:}

I. Reforma política y opinión pública

II. Reelección y democracia

III. Segunda vuelta electoral

IV. Candidaturas independientes

V. Financiamiento de campañas electorales.

Contratación de tiempos en medios de comunicación masiva

VI. Distribución de tiempos en medios de comunicación masiva

VII. Relaciones de control entre los poderes Ejecutivo y Legislativo

VIII. Transformaciones de la política

IX. Bibliografía

* Investigadores en el área de Investigación Aplicada y Opinión del Instituto de Investigaciones Jurídicas de la UNAM. 
Ante la ausencia de estudios sobre las actitudes de la población hacia la reforma política, en la Segunda Encuesta Nacional de Cultura Constitucional 2011 se plantearon algunas preguntas que permitieran analizar la opinión pública sobre dicho tema. La opinión de los ciudadanos sobre esos asuntos específicos sólo puede comprenderse si se estudian también los elementos principales de su contexto sociocultural, por ello una de las secciones de la encuesta se encaminó al análisis de las opiniones sobre algunos temas de la reforma política que se complementan con el nivel de información y los valores y actitudes democráticos y autoritarios.

Esta encuesta, réplica de la Primera Encuesta Nacional de la Constitución levantada en 2003, fue diseñada por el Área de Investigación Aplicada y Opinión del Instituto de Investigaciones Jurídicas de la UNAM. Consta de 2208 entrevistas cara a cara, en vivienda a personas de 15 años y más, y fue levantada en mayo de $2011 .^{1}$

\section{Reforma política y opinión pública}

Como consecuencia de la puesta en práctica de la reforma política aprobada en 2007 y de los cambios a la Constitución y al Código Federal de Instituciones y Procedimientos Electorales, se planteó una polémica alrededor de los distintos temas luego de su aplicación por primera vez en las elecciones de 2009. Ello trajo como consecuencia la propuesta de iniciativas provenientes de distintos actores políticos y de la sociedad civil que cristalizaron en nueve iniciativas y cuatro documentos entregados al Congreso de la Unión.

Las demandas se han centrado en una mayor participación y escrutinio de los ciudadanos en la política por distintas vías: reelección legislativa, iniciativa ciudadana $y$, sobre todo, candidaturas a cargos de elección popular independientes de los partidos políticos. De hecho, todas y cada una de las propuestas ya habían sido planteadas con anterioridad pero no se les había dado el canal ni la importancia para ser consideradas y puestas en marcha.

1 El diseño de la muestra permite analizar cuatro regiones del país con un error de estimación de + /- 2.85 para un nivel de confianza del $95 \%$. 
Hoy de nuevo cobra fuerza la demanda por una reforma política, por una mejora de la calidad de la política y de los políticos. Si bien, en principio esta demanda se había manifestado en acciones aisladas de algunos sectores, como, por ejemplo, el llamado a anular el voto que pese a la débil respuesta de la población, duplicó durante el proceso electoral de 2009 la cantidad de votos anulados con relación a 2006; ${ }^{2}$ en contraste, los procesos electorales de 2010 se caracterizaron por elecciones competidas y con altas tasas de participación.

Varios factores, entre ellos, el desinterés de la gente en la política y el desconocimiento de los temas por el público, a los que se aúna la dificultad de hacer coincidir las diversas voluntades e intereses, hacen de la reforma política un tema para el que rara vez se encuentren coyunturas favorables. Varios meses después de las elecciones de 2009 se presentaron las iniciativas para la reforma política que se pretendía aprobar antes del proceso electoral de 2012. Hoy esta posibilidad se pospone hasta después de las próximas elecciones federales.

Dentro de las nueve iniciativas presentadas por los partidos políticos y el Ejecutivo es posible distinguir ocho grandes temas a discusión en los que se agrupan alrededor de cuarenta cambios propuestos cuyos temas principales son: democracia representativa, democracia participativa, sistema de partidos, integración de los poderes legislativos federal y locales, equilibrio de poderes, rendición de cuentas y responsabilidades de los servidores públicos, procuración de justicia y Poder Judicial; sin embargo, no en todos ellos había coincidencias.

Los escasos puntos en común de las nueve iniciativas son: reelección legislativa, reelección de autoridades municipales, candidaturas independientes y ratificación del gabinete por parte del Senado.

Tomando en cuenta las cuarenta propuestas de cambio y los escasos puntos en común, finalmente se aprobó en la Cámara de Senadores el 26 de abril de 2011 un dictamen realizado por las comisiones de Puntos Constitucionales, Reforma del Estado y Estudios Legislativos que únicamente incluye cambios en materia de iniciativa ciudadana, consulta popular, candidaturas independientes, iniciativa presidencial preferente, observaciones del Ejecutivo al Presupuesto de Egresos de la Federación, reconducción de aprobación del presupuesto, sustitu-

2 Según cifras oficiales del Instituto Federal Electoral, los votos anulados durante el proceso electoral de 2009 fueron 1867729 de un total de 34560344 , es decir, el 5.4\% de la votación; mientras que en 2006, en la elección de diputados federales se contabilizaron como nulos 1033665 de un total de 41195198 votos, es decir el 2.5\% de la votación. 
ción del presidente en caso de falta absoluta, reelección de legisladores, ratificación por el Senado de comisionados de órganos reguladores e integración de la Asamblea Legislativa del Distrito Federal.

En las diez propuestas aprobadas en el Senado sólo se tocaron cuatro de los ocho grandes temas presentados (democracia representativa, democracia participativa, integración de los poderes legislativos locales y equilibrio de poderes) lo que evidencia que el largo proceso de negociación entre partidos tuvo resultados que fructificaron en un dictamen mucho más abundante que los simples puntos en común entre iniciativas. Es importante destacar que un punto común entre las iniciativas, la reelección de las autoridades municipales, no fue incluido en el dictamen final aprobado por la cámara de origen. No obstante, el dictamen convertido ya en minuta, no fue aprobado en la Cámara de Diputados, se concluyó que se requería una mayor discusión y consulta con la ciudadanía y se calendarizó un programa de foros de debate para los meses de junio a agosto de 2011. Con esto se canceló la reforma política para el proceso electoral de 2012.

El dictamen propuesto de reforma política no fue aprobado debido a diferencias entre el Partido Revolucionario Institucional, el Partido Acción Nacional y el Partido de la Revolución Democrática en los temas de reelección legislativa, candidaturas ciudadanas, observaciones del Ejecutivo al presupuesto de egresos de la federación, reconducción de aprobación del presupuesto e integración de la Asamblea Legislativa del Distrito Federal. En este punto es importante mencionar que mientras el Partido Acción Nacional aceptó y firmó sin modificación alguna la minuta del Senado - aunque reconoció que la reforma se quedó corta en los (sub)temas de segunda vuelta electoral y reducción de las cámaras del congreso-, tanto el PRI como el PRD reconocieron que hace falta hacer modificaciones en la minuta proveniente del Senado de la República.

Así, de diez propuestas que incluía el dictamen votado en el Senado, las únicas coincidencias que se encuentran entre la cámara alta y la cámara baja se reducen a cinco propuestas que son: iniciativa ciudadana, consulta popular, ratificación por el Senado de comisionados de órganos reguladores, sustitución del presidente en caso de falta absoluta e iniciativa presidencial preferente.

En la Encuesta Nacional de Cultura Constitucional se tomaron los temas más representativos y los más discutidos de la reforma política para conocer las opiniones, sentimientos y actitudes sobre algunos de 
los temas discutidos: reelección, segunda vuelta electoral, candidaturas independientes, contratación de tiempos en medios de comunicación masiva, distribución de tiempos en medios de comunicación masiva y control del Ejecutivo por el Legislativo.

\section{Reelección y democracia}

La ideología de la revolución mexicana que dio sustento al Estado mexicano ha declinado en su discurso y algunos de sus contenidos parecen haber perdido su vigencia; no obstante, varios de sus principios permanecen profundamente arraigados en el imaginario de la población. Permanece la idea de un Estado laico y como base fundamental del sistema, el principio de la no reelección. En México, la reelección se vincula en el imaginario social a un régimen dictatorial, al mismo tiempo que la cultura de exigencia de rendición de cuentas no está presente en la mayoría de la población, que no contempla a la reelección como un instrumento útil para la premiación o el castigo a la labor de un funcionario.

Históricamente en México la reelección se ha asociado con la existencia de una dictadura y la no reelección con la lucha por la democracia, debido a la memoria del movimiento revolucionario de 191017. Los cambios acontecidos en el país durante los últimos años y las demandas por la democratización nos llevaron a explorar qué tanto han cambiado o no las percepciones de la población acerca de la relación entre la reelección y la democracia.

La reelección es uno de los componentes más discutidos de la potencial reforma electoral. Las resistencias a la reelección consecutiva están fincadas tanto en la opinión pública como en los líderes de los partidos políticos. En primer lugar, la opinión pública ve a los políticos con desconfianza severa; en segundo, los líderes de los partidos no quieren perder el control de sus bancadas en el Congreso al permitir que los ciudadanos decidan quiénes permanecen en sus curules. Sin embargo, la reelección consecutiva es un mecanismo eficiente para generar rendición de cuentas: si los políticos (y los partidos) quieren conservar sus puestos de elección popular, deberán convencer al electorado de que los merecen. De esta forma, la permanencia de los políticos en sus puestos de elección popular estará determinada no 
sólo por los caprichos de los líderes de su partido, sino también por su desempeño al promover políticas públicas que atiendan a los intereses de su electorado.

Esta "conexión electoral" (Mayhew 2004) favorece el acercamiento de los candidatos a sus distritos y puede, potencialmente, promover una relación más positiva entre los representantes y quienes votan por ellos. Los votantes ganan incentivos para conocer a sus representantes y enterarse de lo que han hecho, mientras que los representantes buscan satisfacer las demandas de su electorado al tiempo que buscan también representar sus intereses. La promesa de continuidad también puede promover políticas públicas diseñadas para el largo plazo, que permitan a los representantes con una carrera política en cargos de elección popular llevarse el crédito por el trabajo realizado. No todo es favorable, sin embargo. La reelección genera incentivos para que los representantes aumenten su presencia en la discusión pública según es reflejada en los medios de comunicación masiva. Esto significa que las campañas electorales de los diputados y senadores aumentarán en su intensidad, lo que complicará aún más la labor de los agentes electorales para controlar y financiarlas.

En 2011 la opinión sobre la reelección se encuentra dividida: el acuerdo con la reelección del presidente obtiene 45\%, mientras que el desacuerdo alcanza a poco más de la mitad de los entrevistados. Con la reelección de los diputados federales estuvo de acuerdo, o de acuerdo en parte el $40 \%$ de los encuestados. Asimismo, crece el acuerdo con la reelección de los senadores, de los gobernadores y presidentes municipales que alcanzan a poco más de un tercio de los entrevistados (véase gráfica1). 


\section{Gráfica 1}

En México no hay reelección, es decir que los funcionarios públicos no pueden volver a ser electos para el mismo puesto. ¿Qué tan de acuerdo o en desacuerdo estaría usted con que pudiera reelegirse...?

(porcentajes)

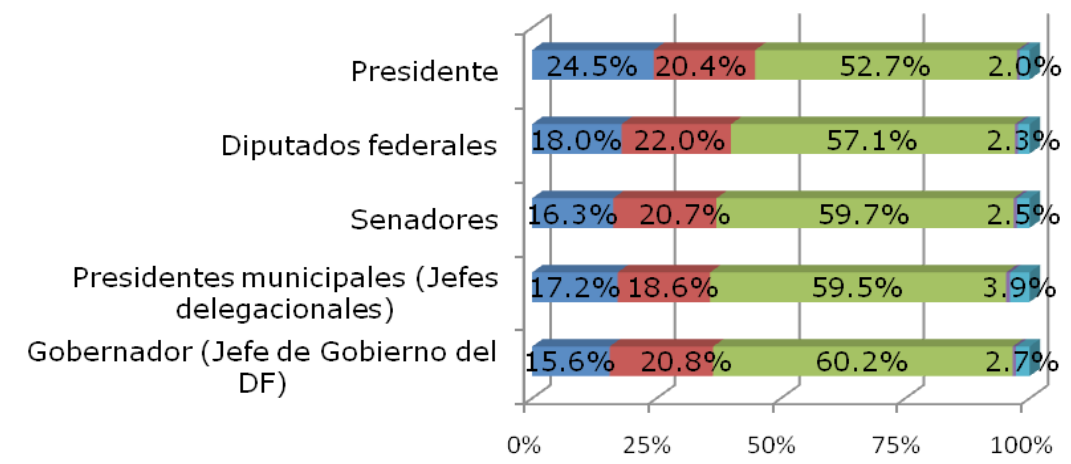

$\square$ De acuerdo $\square$ De acuerdo, en parte $\square$ En desacuerdo $\square$ Otra $\square$ NS/NC

Fuente: Segunda Encuesta Nacional de Cultura Constitucional, México, UNAM, Instituto de Investigaciones jurídicas, 2011.

Estarían más de acuerdo con la reelección del presidente de la República los jóvenes entre los 15 y 29 años, las personas con mayor ingreso, quienes habitan en el sur del país, las personas que dijeron identificarse con el PAN, el PT y el PVEM. Con la reelección de los diputados federales estuvieron más de acuerdo las personas que se identifican con el PT y el PVEM y quienes no se identifican con ningún partido, así como los que habitan en el sur y centro del país.

La oposición a la reelección es aún mayoritaria. Más de la mitad de las personas entrevistadas consideran que no se debería reelegir al presidente de la República, diputados, senadores, gobernadores o presidentes municipales. No obstante, existen confusiones sobre los efectos posibles de la reelección como se observa en las siguientes preguntas.

En la Segunda Encuesta Nacional de Cultura Constitucional se plantearon preguntas adicionales para recoger las percepciones del público sobre la reelección de los diputados federales en relación con 
su desempeño, en torno a la idea de que la reelección constituiría un acicate para el mejoramiento de su función. A la pregunta, ¿Con cuál de las siguientes frases está usted más de acuerdo...? Si en México hubiera reelección los diputados harían mejor su trabajo para que la gente los reelija o los diputados seguirían trabajando igual que hasta ahora, la opinión se muestra dividida: un $40.2 \%$ considera que los diputados harían un mejor trabajo, particularmente los jóvenes, las personas con más altos niveles de escolaridad y quienes no cuentan con ninguna, quienes habitan en ciudades medias y quienes habitan en el sur del país. En contraste, piensan que los diputados seguirían trabajando igual que ahora los varones, los adultos de 65 años y más quienes tienen menores niveles de escolaridad y quienes habitan en las regiones centro y centro-occidente del país (véase gráfica 2).

\section{Gráfica 2}

¿Con cuál de las siguientes frases está usted más de acuerdo? (porcentajes)

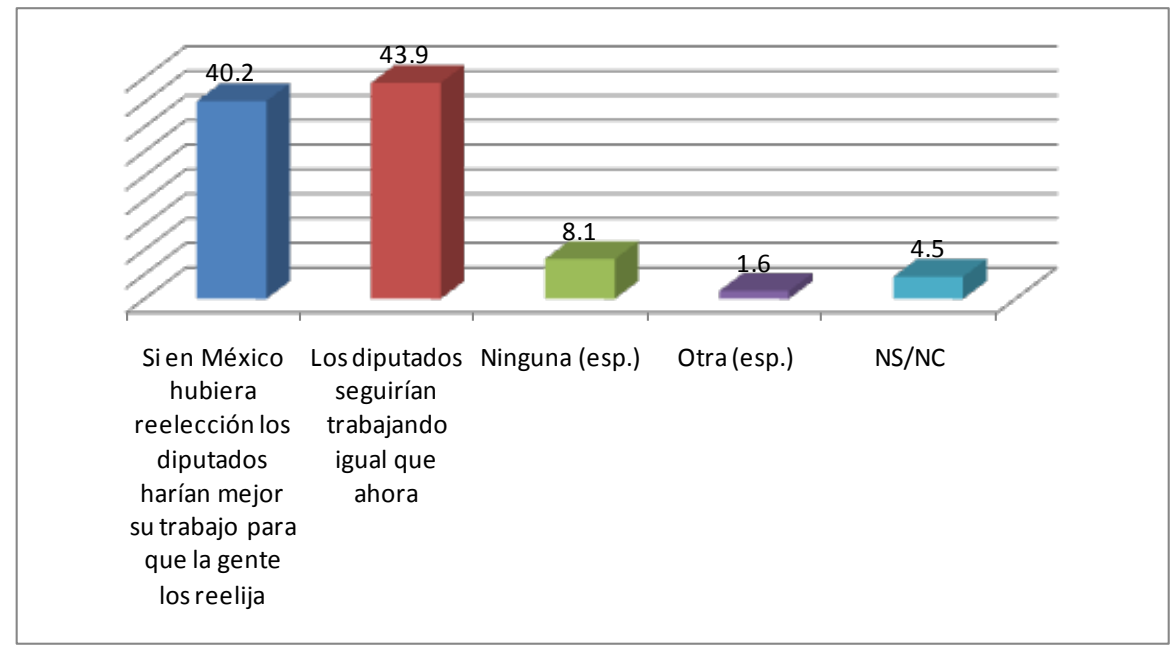

Fuente: Segunda Encuesta Nacional de Cultura Constitucional, México, UNAM, Instituto de Investigaciones Jurídicas, 2011.

Con el propósito de conocer la disposición de los entrevistados a premiar o castigar con su voto el desempeño de los diputados se planteó la pregunta: Si hubiera reelección en México y su diputado hubiera 
hecho un buen trabajo, ¿Votaría ud. por él otra vez? Cuatro de cada diez entrevistados señalaron que votarían de nuevo por ese diputado, entre ellos, las personas con mayores niveles de escolaridad, quienes se identifican con el PAN, quienes habitan en las grandes ciudades y en el norte del país. Dijeron que preferirían votar por otra persona un poco más de uno de cada cuatro entrevistados, y menos de uno de cada diez señalaron que preferirían no votar (véase gráfica 3 ).

\section{Gráfica 3}

Si hubiera reelección en México y su diputado hubiera hecho un buen trabajo, ¿Votaría ud. por él otra vez?

(porcentajes)

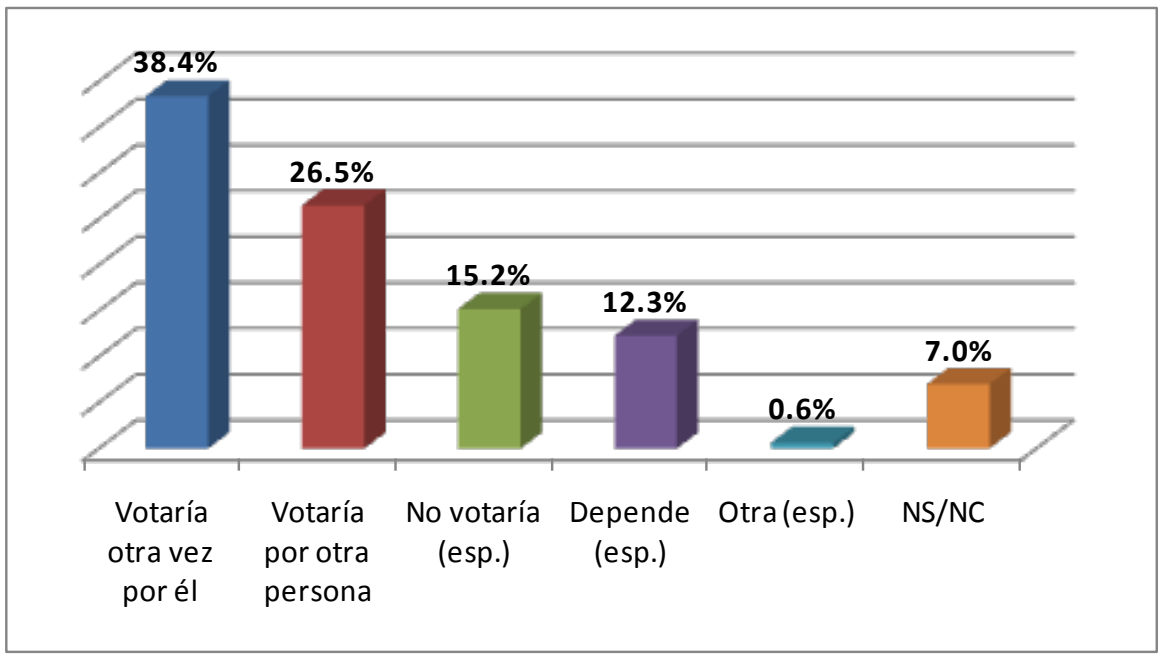

Fuente: Segunda Encuesta Nacional de Cultura Constitucional, México, UNAM, Instituto de Investigaciones Jurídicas, 2011.

En la sociedad comienza a crecer paulatinamente y expresarse una corriente de opinión en favor de la reelección, que tiende a aumentar de 1998 a la fecha, y abarca a los jóvenes, los estratos altos de escolaridad e ingreso, no obstante, todavía no es mayoritaria. 


\section{Segunda vuelta electoral}

El mecanismo de la segunda vuelta implica la celebración de una segunda elección en la que compiten solamente los dos candidatos que obtienen los porcentajes más altos de votación en una primera contienda abierta a todos los candidatos elegibles. Cualquier elección, ya sea de primera o segunda vuelta, es asumida como la expresión de una serie de preferencias individuales que, al ser agregadas, arrojan al candidato preferido por la mayoría, ya sea relativa o absoluta.

La segunda vuelta tiene el objetivo expreso de garantizar una mayoría absoluta de los votos al candidato ganador (es decir, el 50\% más uno de la votación), con la intención de reducir la ambigüedad de las contiendas electorales cerradas y los potenciales riesgos a la legitimidad del ganador y del régimen democrático. Por ejemplo, las complicaciones que siguieron a la elección presidencial de 2006 pudieron haberse mitigado de existir la segunda vuelta que confirmara ante la opinión pública y ante los actores políticos relevantes que Felipe Calderón había ganado la elección.

Este argumento, sin embargo, se enfrenta a la posibilidad de que de existir la segunda vuelta y dados el muy cerrado margen de la elección y la inestabilidad de las preferencias de la mayor parte del electorado (Flores-Macías, 2009), el margen entre ambos candidatos fuera cerrado también (lo que no resuelve el problema de legitimidad del ganador) y aun peor para la credibilidad del sistema electoral mexicano, el ganador resultara ser el candidato que en la primera ronda obtuvo el segundo lugar. Este escenario resulta ciertamente poco plausible. Sin embargo, las variables cruciales para explicar el comportamiento de los electores en un escenario de segunda vuelta no han sido cabalmente exploradas.

A la pregunta planteada en la Segunda Encuesta Nacional de Cultura Constitucional, en el caso de que una elección para presidente resultara muy cerrada, cuatro de cada diez personas entrevistadas creen que se debería declarar ganador al partido que obtuvo más votos. Tres de diez respondieron que se debería organizar una nueva elección entre los dos primeros lugares y poco menos de la cuarta parte respondió, espontáneamente, que se debería hacer un recuento de votos (véase gráfica 4). 


\section{Gráfica 4 \\ Si una elección para presidente resultara muy cerrada, en su opinión ¿Qué se debería hacer? \\ (porcentajes)}

Declararganador al partido que obtuvo más votos

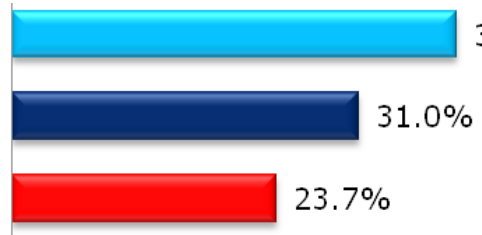

$39.8 \%$

Organizar una nueva elección entre los dos primeros lugares ó

Hacer recuento de votos (esp)

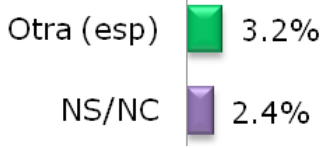

Fuente: Segunda Encuesta Nacional de Cultura Constitucional, México, UNAM, Instituto de Investigaciones Jurídicas, 2011.

Algunas de las preguntas aún abiertas a discusión son las siguientes: ¿cuál es la probabilidad de que vuelvan a las urnas una segunda vez los votantes que en la primera ronda votaron por alguno de los dos partidos participantes? Cualquier diferencia en la motivación o en la movilización de ambos grupos de electores puede alterar el porcentaje de votos que reciba cada partido en la segunda visita a las urnas. La siguiente pregunta concierne a los votantes que no seleccionaron a alguno de los participantes en la segunda vuelta, ¿por qué partido votarán, si acaso acuden a votar, en la segunda vuelta? Esta pregunta no es trivial: dada la multidimensionalidad del espacio ideológico en las elecciones en México y de nuevo, dada la inestabilidad de las preferencias electorales, muchos de estos votantes pueden decidir acudir a votar por alguno de los dos contendientes si figuran entre su segunda preferencia (siendo la primera preferencia la que expresaron en la primera ronda) de forma que no corresponda cabalmente con sus intereses ideológicos (asumiendo que los tenga).

Las particularidades del electorado mexicano pueden introducir inestabilidades en los resultados de la segunda vuelta: los sufragios de los votantes que expresan sus segundas preferencias pueden no tener una correspondencia clara con un espacio ideológico básico como es, por ejemplo, la distinción entre partidos de izquierda, centro y dere- 
cha. Por ejemplo, un perredista que acuda a las urnas en una segunda vuelta entre un candidato priísta y otro panista bien puede votar por el PAN, ya que no quiere apoyar un candidato del viejo régimen, aunque es probable que un candidato priísta favorecería políticas públicas más cercanas a sus intereses. El problema no radica tanto en la expresión de las preferencias electorales, las cuales pueden no tener un ordenamiento claro, sino más bien en la inestabilidad que introducirían en los resultados electorales en una segunda vuelta. Especialmente en escenarios en los que los resultados electorales son cerrados, dicha inestabilidad en la expresión de preferencias de los votantes partidistas y no partidistas pueden generar resultados que posiblemente no reflejen cabalmente (aunque así sea su cometido inicial) las preferencias de los votantes mexicanos.

\section{Candidaturas independientes}

Por lo que respecta a las candidaturas independientes para acceder a algún cargo de elección popular en México, aún no se encuentra esta figura regulada, ya que el artículo 41 constitucional deja esta facultad exclusivamente a los partidos políticos.

Las candidaturas independientes buscan abrir espacios políticos en un paisaje, la aparición de nuevas opciones políticas está limitada por los liderazgos jerárquicos de los partidos existentes y sus listas cerradas de candidatos a puestos de elección popular. Puede decirse que los partidos políticos existentes y representados en el congreso actúan como un cártel - lo que los economistas llaman un oligopolio-que protege a sus miembros cerrando el acceso de nuevos actores al juego electoral y legislativo. Las leyes electorales existentes, tales como las listas cerradas de candidatos (que controlan el acceso de los miembros del partido a puestos de elección popular) o como los umbrales de votación a los que está condicionada la continuidad del registro de los partidos (que limitan el número de partidos que tienen acceso al Congreso), pueden explicarse como estrategias diseñadas para controlar (y limitar) las opciones políticas que son presentadas a la ciudadanía antes de cada elección (Lijphart, 1999). Las candidaturas independientes buscan evadir estas restricciones y permitir a candidatos 
ajenos a la constelación existente de partidos acceder a la competencia electoral.

Esta propuesta encuentra, entre otras, dos objeciones importantes: la primera corresponde a la forma como los candidatos independientes embonarían en el sistema existente de financiamiento oficial de los partidos; la segunda corresponde a los efectos que tendría en materia de acceso a los medios electrónicos de comunicación. El primer problema significa llevar a cabo un ejercicio de rediseño constitucional que requiere acomodar los esfuerzos de promoción de candidatos que, al carecer de un partido, no figuran en las fórmulas actuales de distribución de recursos. En segundo lugar, si las candidaturas ciudadanas han de tener un impacto no trivial en la contienda electoral, requieren que los candidatos alcancen un nivel significativo de exposición mediática cuyo costo tendría que ser cubierto por el presupuesto destinado a los tiempos oficiales.

En la Segunda Encuesta Nacional de Cultura Constitucional, aunque las candidaturas ciudadanas reciben el apoyo de cuatro de diez entrevistados, más de la mitad prefiere que los candidatos pertenezcan a un partido político (véase gráfica 5).

\section{Gráfica 5}

¿Cuál de las siguientes frases se acerca más a los que usted piensa? (porcentajes)

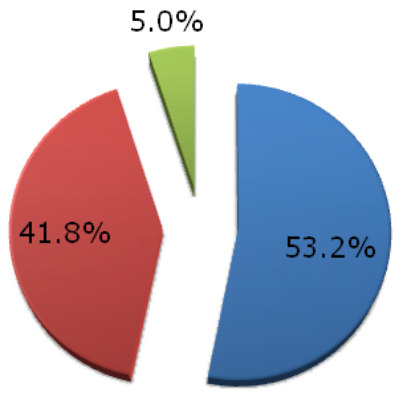

Es necesario que los candidatos en las elecciones pertenezcan a un partido político o

Los candidatos pueden ser personas que no pertenezcan a algún partido político

$\square \mathrm{NS} / \mathrm{NC}$

Fuente: Segunda Encuesta Nacional de Cultura Constitucional, México, UNAM, Instituto de Investigaciones Jurídicas, 2011.

Este resultado puede ser muestra del creciente descontento social frente a los partidos políticos. No obstante, es importante notar que la etiqueta partidista de un candidato proporciona información impor- 
tante a los votantes sobre el espectro de políticas públicas que el candidato en cuestión podría poner en práctica si fuera elegido, así como sobre el grupo político al que pertenece y sobre el cual los votantes también pueden tener preferencias formadas (como ejemplo, considérese el voto a favor o en contra del PRI) (Ansolabehere, 2006). Carecer de dicha etiqueta aumenta el costo que un candidato independiente tendría que pagar, en términos de la información que tendría que proveer a los votantes potenciales y la intensidad con la cual tendría que transmitir dicho mensaje a la opinión pública, para contender creíblemente en la elección. Finalmente, esta brecha informativa abre la posibilidad de la entrada de candidatos independientes cuya campaña esté basada en consideraciones de tipo carismático o en plataformas antisistémicas que exploten nichos de descontento y desconfianza institucional en el electorado.

\section{Financiamiento de campañas electorales. Contratación de tiempos en medios de comunicación masiva}

El artículo 41 constitucional en su fracción tercera dispone que los partidos políticos nacionales tendrán derecho al uso de manera permanente de los medios de comunicación social, y posteriormente en la parte final de la misma fracción, en su apartado A, dispone una prohibición expresa para los particulares en la contratación de publicidad política en los medios de comunicación, y para describir con mayor claridad es necesario citar dicha referencia:

Los partidos políticos en ningún momento podrán contratar o adquirir, por sí o por terceras personas, tiempos en cualquier modalidad de radio y televisión.

Ninguna otra persona física o moral, sea a título propio o por cuenta de terceros, podrá contratar propaganda en radio y televisión dirigida a influir en las preferencias electorales de los ciudadanos, ni a favor o en contra de partidos políticos o de candidatos a cargos de elección popular. Queda prohibida la transmisión en territorio nacional de este tipo de mensajes contratados en el extranjero.

Con relación a los tiempos y goce de transmisión de los anuncios de los partidos políticos en los medios de comunicación social se estable- 
ce una regulación puntual por parte de nuestra Constitución, la cual en el artículo 41, fracción III, apartado A, realiza diversas salvedades:

Apartado A. El Instituto Federal Electoral será autoridad única para la administración del tiempo que corresponda al Estado en radio y televisión destinado a sus propios fines y al ejercicio del derecho de los partidos políticos nacionales...

Esta redacción del artículo citado, junto con la distribución de recursos, fue considerada la parte medular de la reforma electoral de 2007, cuya amplia discusión y participación de los medios de comunicación no tiene precedente. Por ello en la Segunda Encuesta Nacional de Cultura Constitucional se preguntó el acuerdo o desacuerdo de las personas sobre la capacidad de los distintos actores políticos para financiar espacios publicitarios en los medios electrónicos de comunicación.

Así, tenemos que los datos recabados muestran que casi la mitad de los entrevistados están de "muy de acuerdo" o "de acuerdo" con que sólo los partidos políticos puedan contratar publicidad política en radio y televisión (véase gráfica 6). Un porcentaje un poco menor está de acuerdo con que los individuos o las agrupaciones de ciudadanos puedan hacer lo mismo.

Igualmente, seis de cada diez entrevistados están "en desacuerdo" o "muy en desacuerdo" con que la Iglesia contrate publicidad política en radio y televisión; más de la mitad de la población entrevistada está "en desacuerdo" o "muy en desacuerdo" con que las empresas hagan lo mismo. 
Gráfica 6

Por lo que usted piensa, ¿qué tan de acuerdo o en desacuerdo está usted con que las personas u organizaciones que no participan en las elecciones, como... puedan contratar publicidad política en radio y televisión?

(porcentajes)

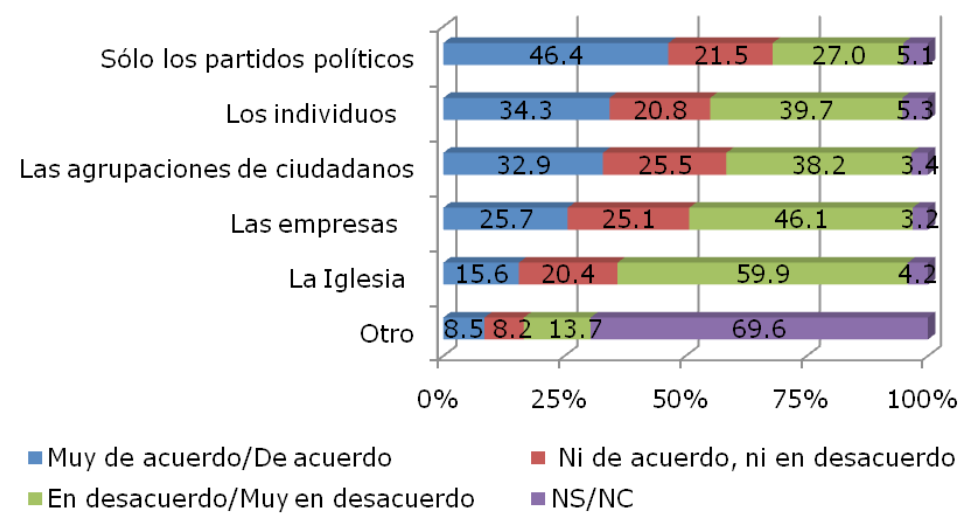

Fuente: Segunda Encuesta Nacional de Cultura Constitucional, México, UNAM, Instituto de Investigaciones Jurídicas, 2011.

\section{Distribución de tiempos en medios de comunicación masiva}

El reparto equitativo de publicidad durante la campaña es un asunto que compete a la distribución de recursos públicos para promover a los candidatos previamente registrados. El principal punto de debate en este respecto es que la distribución de los recursos a todos los partidos sea de forma proporcional o igualitaria para todos. Un argumento a favor de la distribución igualitaria de los recursos para publicidad durante las campañas es la apertura de espacios mediáticos a opciones políticas nuevas o poco conocidas, permitiéndoles alcanzar públicos nuevos. Una consecuencia de esto sería favorecer la pluralidad en las campañas políticas.

El problema con este argumento es doble, sin embargo. En primer lugar, la ya citada volatilidad de las preferencias electorales de los ciudadanos mexicanos (producida, en parte, por la falta de posiciones ideológicamente distinguibles entre los partidos políticos) favorecería la dispersión de las preferencias electorales, las que bien pueden 
dirigirse a opciones políticas carentes de contenido sustantivo; baste como ejemplo la campaña de "uno de tres" promovida por el Partido Nueva Alianza durante 2006 que facilitó que el partido superara el umbral requerido para mantener el registro, al tiempo que no proponía nada políticamente significativo.

En segundo lugar, dado que los ciudadanos deciden por cuál partido votar tomando en cuenta primordialmente la identificación partidista del candidato (dando pie a los llamados "efectos mínimos" de las campañas), el aumento en la presencia de los partidos pequeños en los medios tendría un efecto limitado en la promoción de nuevas opciones. Ambas objeciones permiten concluir que la distribución equitativa de los recursos públicos para las campañas tendría una utilidad limitada para promover la pluralidad electoral en el país - a menos, desde luego, que dichas campañas tuvieran un contenido ideológicamente sustantivo-, lo cual en sí mismo no es garantía de generarle más votos al partido que las proponga dadas las limitaciones temporales y el escaso interés que los ciudadanos generalmente muestran en las campañas.

Al indagar sobre la distribución de los tiempos a los partidos políticos en los medios de comunicación masiva, la mayoría de los entrevistados, más de siete de cada diez se inclinan porque todos los partidos reciban la misma cantidad de anuncios en radio y televisión sin importar su votación (véase gráfica 7).

\section{Gráfica 7}

¿Cuál de las siguientes frases se acerca más a los que usted piensa? (porcentajes)

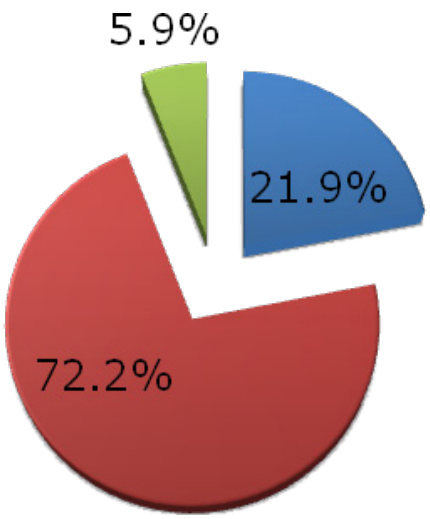

Que los partidos que tienen más votos se les repartan más anuncios en radio y $\mathrm{TV}$

Que todos los partidos sin importar su votación reciban la misma cantidad de anuncios en radio y TV

$\square \mathrm{NS} / \mathrm{NC}$

Fuente: Segunda Encuesta Nacional de Cultura Constitucional, México, UNAM, Instituto de Investigaciones Jurídicas, 2011. 
Estuvieron de acuerdo con que todos los partidos políticos reciban la misma cantidad de anuncios en radio y televisión las personas jóvenes y los mayores de sesenta años, quienes obtienen menores ingresos, las personas con secundaria y preparatoria incompleta, quienes habitan en el sur del país y los que dijeron identificarse con el partido Convergencia y quienes no se identifican con ningún partido político.

\section{Relaciones de control entre los poderes Ejecutivo y Legislativo}

Durante décadas de gobiernos en los que el presidente de la República controlaba el partido en el gobierno y, con ello, las cámaras en el Congreso de la Unión, el gobierno funcionaba a fuerza de su falta casi total de pluralidad bajo el mando del jefe del Ejecutivo. Este hecho, frecuentemente olvidado, explica por qué el presidente era una figura tan poderosa; aunque institucionalmente se trate de un presidente con pocas herramientas para actuar de forma independiente del Congreso si éste es controlado por un partido diferente y decide no cooperar con sus propósitos. La percepción sobre la casi omnipotencia del presidente, aunada a un cierto culto a la personalidad y a la tendencia de los votantes a adjudicarle la responsabilidad de lo que sucede en la sociedad y en la economía, genera una fuerte inercia en la opinión pública a considerar que el poder de éste para tomar decisiones debe ser limitado por el Congreso de la Unión.

En el contexto de este debate sobre las facultades del Ejecutivo y Legislativo, a la pregunta de si los diputados y senadores deberían autorizar al presidente el uso de las fuerzas armadas para mantener la seguridad del país, ocho de cada diez personas consideran que los diputados deberían aprobar o aprobar en parte el programa de gobierno, un porcentaje similar opina que el Congreso de la Unión debe aprobar los nombramientos de los secretarios de Estado o el uso de las fuerzas armadas para mantener la seguridad del país (véase gráfica 8). 


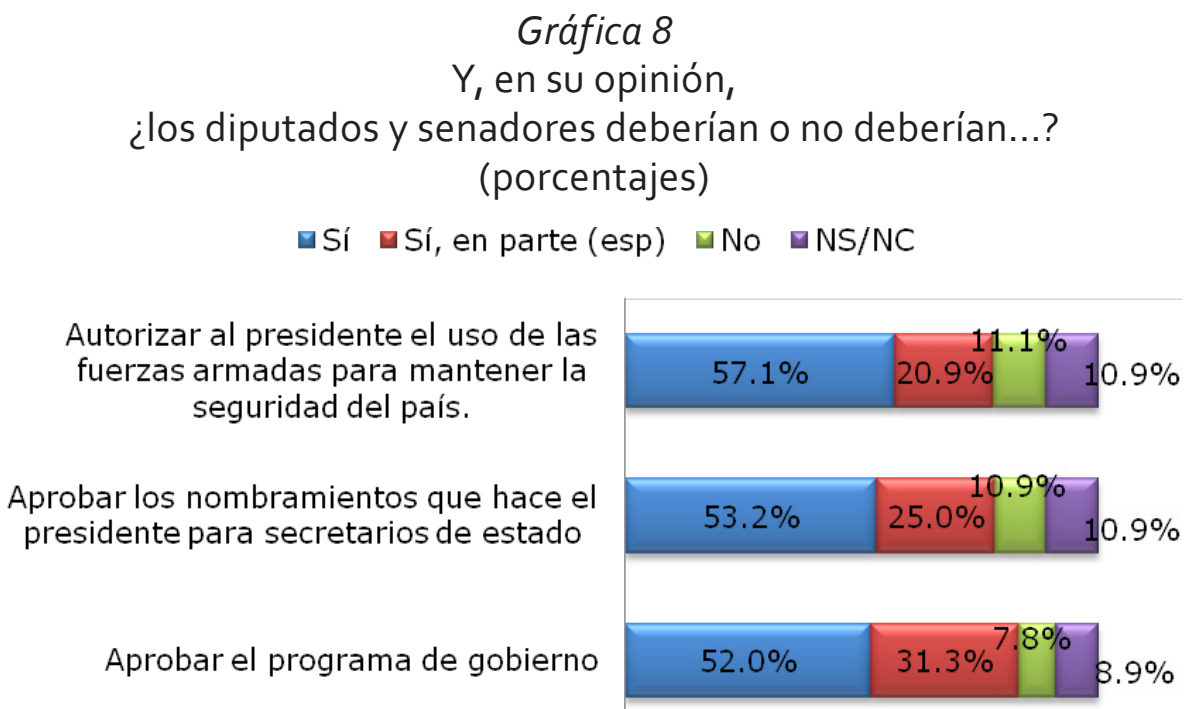

Fuente: Segunda Encuesta Nacional de Cultura Constitucional, México, UNAM, Instituto de Investigaciones Jurídicas, 2011.

Están más de acuerdo con esta afirmación los jóvenes, al igual que las personas de 55 años y más, quienes cuentan con mayores niveles de escolaridad e ingreso, las personas que habitan en las grandes urbes y en el norte del país, así como quienes dijeron identificarse con el PRI, PT, PVEM y quienes señalaron que no se identifican con ningún partido político.

\section{Transformaciones de la política}

Las percepciones y opiniones consignadas a lo largo de este texto, como la tendencia hacia la resolución de los problemas en nuevos tiempos y espacios, y por medios nuevos y distintos, expresan el inicio de transformaciones en una cultura política autoritaria.

Estos cambios se combinan con viejas nociones y prácticas arraigadas en nuestra cultura. Fenómenos como la voluntad de participación ciudadana y las nuevas formas de entenderla, reflejan no sólo un cambio cultural, sino el surgimiento de nuevas concepciones sobre la política y la creación de nuevas formas de relación con el poder. Las nuevas formas de ser y hacer política se encuentran aprisionadas en 
viejos canales que hoy resultan estrechos, lo que se refleja en un desgaste acelerado del poder y de la credibilidad de los actores políticos.

Nuestra sociedad cambia y a la vez desea cambios, mas los concibe como graduales, los matiza. Así, el cambio político tendrá que comprender no sólo reformas a las leyes electorales y las reglas del juego político, sino también una transformación de los modos de entender la política y los horizontes a partir de los cuales se practica. Una reforma política, implica ante todo, una reforma de la política y con ello, la creación de una cultura que le dé sustento.

Se manifiesta una percepción de desigualdad sobre algunas de las condiciones de la competencia política y una opinión dividida sobre las causas principales de los conflictos electorales, lo que posiblemente reflejaría una cierta inseguridad sobre los marcos jurídico-políticos existentes.

Lo anterior plantearía como necesaria la revalorización de los procedimientos institucionales, un ajuste del comportamiento a reglas que hagan previsible y confiable la acción del otro, elementos que confluyen en una respuesta positiva a la necesidad de la reforma.

De lo anterior se desprende que, de llevarse a cabo una reforma, sus efectos tendrían que ser palpables a la ciudadanía, no sólo mediante los cambios en la legislación, sino también en la práctica política cotidiana. Esto es, la reforma no sólo debería tener un sentido, sino que tendría que ser generadora de nuevos sentidos y prácticas y concordar tanto con las concepciones y ritmos del cambio, como con los valores y representaciones de la población.

La cultura política de los mexicanos está cambiando. Surgen nuevas formas de actuar en el terreno de lo público que antes no se consideraban como políticas. No obstante, no se ha resuelto aún la manera en que han de articularse con las normas y prácticas tradicionales. El encuentro y el desfase de los problemas y las soluciones de ayer y de hoy originan las distintas apreciaciones sobre la política en México.

Emergen discursos democráticos y en un proceso sutil, las prácticas y símbolos tradicionales se modifican para adecuarse a los nuevos tiempos; sin embargo, esas prácticas y esos símbolos constituyen el contexto en el que se juzgarán los cambios. 


\section{Bibliografía}

Ansolabehere, S., "The Paradox of Minimal Effects", en Johnston, R. y Brady, H. E. (eds.), Capturing Campaign Effects, Ann Arbor, University of Michigan Press, 2006.

Bidart Campos, Germán, El derecho de la Constitución y su fuerza normativa, México, UNAM, Instituto de Investigaciones Jurídicas, 2003.

Camargo, Pedro Pablo, Reelección presidencial y parlamentaria en América y México, México, UNAM, 1965.

Flores-Macías, Francisco, "Electoral Volatility in 2006", en DomíNGUEZ, Jorge I. et al. (eds.), Consolidating Mexico's Democracy; the 2006 Presidential Campaign in Comparative Perspective, Baltimore, Jonhns Hopkins University Press, 2009.

Lijphart, Arend, Patterns of Democracy; Government Forms and Performance in Thirty-Six Countries, Yale University Press, 1999.

Mayhew, David R., Congress; The Electoral Connection, Yale University Press, 2004.

Encuesta Nacional de Reelección e Impartición de Justicia, México, UNAM, Instituto de Investigaciones Jurídicas, 1998.

Encuesta Nacional Cultura de la Constitución, México, UNAM, Instituto de Investigaciones Jurídicas, 2003.

Segunda Encuesta Nacional de Cultura Constitucional, México, UNAM, Instituto de Investigaciones Jurídicas, 2011.

Varios autores, La reforma político-electoral y su contexto sociocultural, IFE-IIS, UNAM, 2006. 